\title{
A produção de vídeos digitais: uma situação de aprendizagem na formação de professores de ciências
}

Murilena Pinheiro de Almeida

Luis Maurício Martins de Rezende

Siumara Aparecida de Lima

\section{Resumo}

O presente estudo tem por propósito analisar as implicações da produção de vídeos digitais enquanto situação aprendizagem interdisciplinar significante, em sala de aula. Em sua consecução fez-se uso da abordagem qualitativa, orientada por um viés exploratório e do delineamento da pesquisa-ação. Participaram deste estudo 30 professores do município de Marechal Thaumaturgo - Acre, licenciandos que á época da realização deste estudo cursaram a disciplina Educação Ambiental componente curricular obrigatório do curso de Licenciatura em Ciências Biológicas da Universidade Federal do Acre em um programa de formação docente em serviço. A produção obtida com esse o processo de ensino articula os problemas socioambientais vivenciados pela comunidade com uma rede de saberes que transitam por vários campos disciplinares conectando-os às práticas sociais, à literatura cientifica. Os recursos tecnológicos podem ser utilizados nas escolas fundamentados em uma ética humanitária e solidária. Portanto, abordar conteúdos de ensino por meio da confecção de vídeos digitais desencadeia um processo de ensino e de aprendizagem capaz de proporcionar uma interação dialógica e dialética entre diversos contextos e vários campos de conhecimentos e saberes. Por um lado, favorece-se a construção de uma mentalidade de respeito à pessoa e ao ambiente, e por outro, permite-se a atuação em redes de informação e viabilizam um processo de emancipação da pessoa, possibilitando uma participação social cada vez mais democrática e eficiente. E da mesma maneira, possibilita aos professores a elaboração dos próprios materiais didáticos com sentidos produzidos e significados negociados com os alunos e com própria comunidade.

Palavras-chave: Situação de aprendizagem, Vídeos digitais, Projetos de investigação, Educação Ambiental, Formação de professores de ciências.

\section{Abstract}

The purpose of this study is to analyze the implications of digital video production situation while significant interdisciplinary learning in the classroom. In his achievement was made use of qualitative approach, guided by a bias exploratory and delineation of action research. The study included 30 teachers from Marechal Thaumaturgo - Acre, undergraduates who will be the time of this study enrolled in the subject Environmental Education obligatory curriculum of the Bachelor's Degree in Biological Sciences, Federal University of Acre in a program of teacher education. The yield with this process of education articulates the social and environmental problems experienced by the community with a knowledge network, passing through various disciplines by connecting them to social practices, the scientific literature. Technological resources can be used in schools based on a humanitarian ethics and solidarity. Therefore, addressing learning 
content through the production of digital video triggers a process of teaching and learning can provide a dialectical and dialogical interaction between different contexts and various fields of knowledge and expertise. On the one hand, favors the construction of an attitude of respect for people and the environment, and secondly, it allows to work in networks of information and enable a process of emancipation of the individual, enabling social participation more democratic and efficiently. Likewise, enables teachers to the development of own produced educational materials with senses and meanings negotiated with the students and the community.

Key words: Projects inquiry, Environment Education, Teachers of science formation. Learning situation, Digital videos.

\section{Introdução}

A realização de um projeto de trabalho, na dinâmica da sala de aula, enseja leituras e a busca por diversas fontes de informação, assim como a comparação entre essas, a produção de significados, a atividade de escrita e reelaboração de ideias, conceitos, valores e pontos de vista. A sistematização de projetos de trabalho (HERNÁNDEZ, 1998) e a elaboração de seus relatórios, em geral produzem textos com características acadêmicas ou próximas a essas. Neste trabalho, além de textos, o principal meio de sistematização dos projetos de trabalho, propõe-se, também, a elaboração de vídeos digitais, no contexto da formação de professores de ciências, sob a forma de projetos de trabalho vinculados à investigação de problemas socioambientais vivenciados pela comunidade, em torno dos quais se desenvolveu a trajetória do presente estudo. Tem-se por propósitos relatar uma experiência pedagógica explicitando-se o processo de elaboração de uma situação de aprendizagem problematizadora e contextualizada para a inserção da temática socioambiental na formação de professores de ciências; verificar as contribuições desse processo para a construção de uma práxis pedagógica orientada para a investigação das necessidades, problemas e conflitos vivenciados na realidade concreta e a aquisição da postura docente reflexiva.

\section{Metodologia}

A realização do presente estudo e a análise de seus desdobramentos se inserem nos pressupostos da Pesquisa-Ação, visto que essa modalidade de pesquisa possibilita "a resolução de um problema coletivo e no qual os pesquisadores e os participantes representativos da situação ou do problema estão envolvidos de modo cooperativo ou participativo" (THIOLLENT, 1994, p.14). A presente situação de aprendizagem foi concebida, acatando-se a solicitação dos alunos, durante a realização da disciplina Educação Ambiental, no curso de Licenciatura em Ciências Biológicas da Universidade Federal do Acre, em um programa de formação docente em serviço, no município de Marechal Thaumaturgo, em 2010. Assim, participaram do presente estudo a professora- 
pesquisadora, os 30 discentes da licenciatura em Ciências Biológicas que exercem a docência, no ensino fundamental e médio, em escolas urbanas e rurais, nas disciplinas ciências e biologia.

Os sujeitos participantes deste estudo têm as trajetórias de suas vidas de alguma forma entrelaçadas, permeadas ou mesmo inscritas na dinâmica da tessitura histórica engendrada entorno do empreendimento gumífero na Amazônia. Alguns são filhos e netos de seringueiros, de regatões, ou mesmo de seringalistas ou patrões, ou ainda assumiram algumas dessas posições sociais em algum momento de suas vidas, outros se assumem como indígenas, ou desses descendem. Há ainda aqueles, dentre esses sujeitos, que não se inscrevem diretamente nessa história, porém são por ela influenciados por meio dos valores, do modo de vida, da visão de mundo, das regras de convívio, e em fim pela cultura tecida nesse contexto singular, da qual se tornam partícipes e tributários.

Esse encontro entre culturas e povos indígenas e não-indígenas propiciou a elaboração da cultura dos seringueiros, na qual a floresta e seus entes tanto os materiais quanto os simbólicos têm centralidade. O que, no entanto, não constitui homogeneidade, mas uma diversidade de representações e referências simbólicas, de formas de apropriação do ambiente assim como de produção de relações sociais. Esse mosaico de diversidade, contudo, conflui para uma identidade cultural vinculada à floresta, conforme apontam estudos antropológicos de (CARNEIRO DA CUNHA e ALMEIDA, 2002; PANTOJA, 2008; POSTIGO et al., 2008).

O processo de coleta de dados se referencia nos trabalhos de Lüdke e André (1986) e Thiollent (1994). Em sua consecução utilizou-se o recurso da filmagem combinado com a observação direta, com anotações em caderno de campo efetuando-se, diariamente, o registro das atividades realizadas no processo de ensino, a própria produção dos sujeitos, as perguntas dos alunos, as dúvidas, as curiosidades, dentre outras ocorrências ocorridas durante a realização da disciplina. Todo o registro das atividades foi compartilhado entre a professora-pesquisadora e os alunos. Para isso, a professora-pesquisadora optou por entregar o equipamento de filmagem aos alunos para que eles mesmos produzissem ao mesmo tempo filmagens e fotografias próprias para a realização das atividades da disciplina e auxiliassem no registro das mesmas.

Para Thiollent (2002, p. 58), no curso de uma pesquisa-ação - a técnica principal, ao redor da qual as outras gravitam, é a do seminário, um espaço-tempo mediador, onde a professorapesquisadora e os sujeitos cumprem as funções de examinar, discutir e tomar decisões a cerca do processo de investigação e ainda, coordenar as atividades dos participantes. Seguindo-se essa diretriz técnica da pesquisa-ação, a professora-pesquisadora e os alunos destinaram, em todos os dias durante o período de realização da disciplina, tempos para discutir, examinar, tomar decisões, elucidar dúvidas, e coordenar as atividades da disciplina. Nesses momentos foram realizadas intervenções pedagógicas dialógicas ao longo do curso de elaboração dos trabalhos e no próprio curso das atividades realizadas. Dessa forma, o desenvolvimento das atividades 
realizadas para a consecução dos objetivos do presente estudo foi balizado pelo emprego da técnica do seminário, o qual cumpriu a seguinte sequência metodológica:

1. Definir o tema de estudo e identificar problemas de possível equacionamento.

2. Caracterizar a problemática na qual estão inseridos os problemas.

3. Constituir grupos de estudo.

4. Centralizar e registrar informações provenientes de diferentes fontes e grupos.

5. Elaborar interpretações. 6. Buscar soluções e definir diretrizes de ação.

7. Acompanhar e avaliar as ações.

8. Divulgar os resultados pelos canais apropriados.

O emprego da técnica do seminário proporcionou um espaço para uma aprendizagem coletiva, que por sua vez, exigiu o acompanhamento e a orientação aos alunos em um viés de trabalho dialógico para a socialização de conhecimentos. Assim, obedecendo a esses pressupostos, o trabalho pedagógico correspondeu à seguinte seqüência de atividades: interesse pela pesquisa, estabelecimento de contrato didático, identificação de problemas, o planejamento do estudo, encontros para sessões de estudo, coleta de dados e elaboração e apresentação dos relatórios de pesquisa e a comunicação oral.

A identificação e formulação dos problemas investigados pelos discentes decorreram da problemática vivenciada localmente, emergida em diálogos entre eles e os professores. 0 desenvolvimento dos projetos se processou em encontros regulares com o intuito de efetivar a troca de informações; possibilitar o diálogo com especialistas de diferentes áreas científicas e tecnológicas atuantes na região; o aprofundamento do estudo da literatura referente ao problema abordado; desenvolver habilidades, hábitos, competências, atitudes e valores necessários à atividade docente e à própria prática da pesquisa científica; assim como, manter a regularidade da produção discente e docente. Intencionou-se, com isso, a concretização de uma situação de aprendizagem interdisciplinar significante, uma intervenção pedagógica para estruturar e reestruturar conceitos, além de realizar uma avaliação dialógica e processual das atividades acadêmicas para retroalimentar a dinâmica do processo de ensino-aprendizagem.

No processo de produção e coleta dos dados, a combinação entre o emprego da técnica de seminário e a sequência de trabalho pedagógico construído com os alunos e os seus desdobramentos, articulados com o registro de suas ocorrências em caderno de campo, possibilitou a emergência de categorias que buscaram dialogar com pressupostos teóricos. Desse modo, as categorias emergidas do contexto da prática possibilitaram um processo de interpretação iterativo, que progride por aproximações sucessivas. E, nessa construção operou-se com um movimento de vai e vem entre reflexão observação e interpretação. 


\section{Resultados e discussão}

No município acreano de Marechal Thaumaturgo muitas escolas ainda não possuem laboratórios de informática. Entretanto, dispõem de leitores de DVD e televisores, sendo esses aparelhos de uso frequente nas escolas. Portanto, aprender a produzir vídeos digitais mostrou-se relevante aos professores que atuam naquele contexto. Muitas pesquisas foram realizadas na região, principalmente relacionadas à temática ambiental, no entanto, essas se encontram em centros urbanos muito distantes do município e mesmo fora do país; e ainda, parte importante dessa produção sobre a região está escrita em línguas estrangeiras, o que também dificulta o acesso ao seu conteúdo aos professores e alunos do ensino fundamental e médio. Isso resulta em poucos materiais produzidos sobre a região, acessíveis aos estudantes do ensino fundamental e médio. Embora, o município conte com a comunicação por telefone, rádio, internet, e repetidoras de duas emissoras de televisão, o "Boca de Ferro" ainda é o instrumento de comunicação mais importante para a população urbana do município.

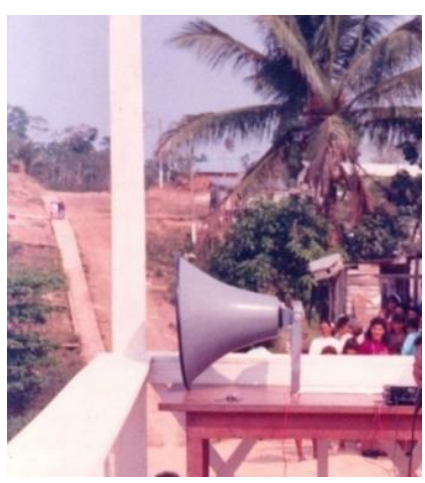

Fotografia 1: Boca de Ferro de Marechal Thaumaturgo - Acre - Fotografia antiga Fonte:

(autor desconhecido)/s.d.

Então, neste contexto de comunicação local, a possibilidade de aprender a produzir vídeos na sala de aula para abordar conteúdos de ensino, na dinâmica de construção dos projetos de trabalho, abre uma perspectiva nova à interação entre os educadores e os seus educandos, assim como, possibilita-lhes o contraponto entre a realidade local e a dimensão global. Autores como (MORAN, 1995), (MARTIANI, 1998), (SHEWBRIDGE; BERGE, 2004), (VARGAS; ROCHA; FREIRE, 2007), elencam os seguintes benefícios para a utilização da produção de vídeos digitais como atividade de ensino e aprendizagem com potencial educacional, ainda a ser explorado: o desenvolvimento do raciocínio crítico; a promoção da expressão e da comunicação; o favorecimento de uma visão interdisciplinar; a integração de diferentes capacidades e

\footnotetext{
'Denominação local do sistema de rádio-auto-falante de responsabilidade da Prefeitura Municipal de Marechal Thaumaturgo usado pelas autoridades do município e pelos munícipes para transmitir notícias, mensagens de interesse público e recados urgentes à população. Funciona regulamente todos os dias, nos horários das 06:30 h às 07:00 h e das 12:00 h as 13:00 h. E eventualmente, quando necessário em outros horários. É similar a uma rádio comunitária.
} 
inteligências e a valorização do trabalho em grupo. Além disso, acolher a essa proposição importa em produzir uma situação de aprendizagem motivadora, pois envolve os alunos no trabalho e confere-Ihes responsabilidades sobre a própria aprendizagem e com o contexto social; coloca-os frente ao uso funcional de diversos tipos de fontes de informação, formas de linguagem e gêneros textuais e assim ler, ouvir, argumentar e produzir textos deixa de ser apenas uma imposição acadêmica e passa a ser uma necessidade, uma demanda do próprio processo de ensino, o qual tem por consequência a lida com as controvérsias presentes no discurso científico; tratar com as controvérsias provoca o debate e argumentação e a compreensão da natureza do conhecimento científico (SANTOS; MORTIMER, 2009).

A abordagem de ensino utilizada no desenvolvimento da Disciplina Educação Ambiental resultou na produção de textos e vídeos. O material elaborado contém imagens, fotografias do contexto socioambiental, assim como entrevistas e depoimentos de moradores e autoridades do município de Marechal Thaumaturgo. No quadro 1, apresentam-se os temas abordados pelos alunos no processo de ensino empreendido:

\section{Trabalhos produtos da Disciplina Educação Ambiental - Curso de Licenciatura em Ciências Biológicas - Programa Especial de Formação de Professores em Marechal Thaumaturgo, Julho de 2009}

\begin{tabular}{|l|l|}
\hline Textos & Vídeos \\
\hline Leishmaniose Tegumentar Americana & Leishmaniose Tegumentar Americana \\
\hline Água: do Rio Juruá até minha casa & Água: do Rio Juruá até minha casa \\
\hline $\begin{array}{l}\text { Hábitos alimentares da população urbana de } \\
\text { Marechal Thaumaturgo }\end{array}$ & $\begin{array}{l}\text { Hábitos alimentares da população urbana de } \\
\text { Marechal Thaumaturgo }\end{array}$ \\
\hline $\begin{array}{l}\text { Transporte, indo e vindo a Marechal } \\
\text { Thaumaturgo - Acre: no rítmo das águas }\end{array}$ & $\begin{array}{l}\text { Transporte, indo e vindo a Marechal } \\
\text { Thaumaturgo - Acre: no ritmo das águas }\end{array}$ \\
\hline $\begin{array}{l}\text { Toxoplasmose: doença transmitida por animais } \\
\text { domésticos em Marechal Thaumaturgo-Acre }\end{array}$ & \\
\hline $\begin{array}{l}\text { Gravidez na adolescência em Marechal } \\
\text { Thaumaturgo }\end{array}$ & \\
\hline $\begin{array}{l}\text { O lixo na cidade de Marechal Thaumaturgo - } \\
\text { Acre }\end{array}$ & \\
\hline
\end{tabular}

$\mathrm{Na}$ condução e pilotagem desse processo de ensino foi crucial para o seu funcionamento o envolvimento dos alunos em suas próprias aprendizagens e em seus trabalhos. A proposição emergida dos alunos, de sistematizar o material produzido em vídeos, inserida no desenvolvimento da disciplina Educação Ambiental, estabeleceu um clima de cooperação entre os alunos, fomentando e alimentando a motivação em concluir um projeto próprio (TAPIA, 2001). Para manter o envolvimento e a cooperação dos alunos, com resultados profícuos, duas orientações foram postas em ação, em uma mesma diretriz pedagógica para o ensino: a de produzir textos e a de produzir vídeos. Nessas duas modalidades de resultado da ação pedagógica 
- os textos e os vídeos - tanto a professora-pesquisadora como os alunos foram intensamente absorvidos pelo trabalho do estudo.

Efetivamente, abordar os conteúdos de ensino por meio da elaboração do vídeo desafia intensamente os alunos. E esses aprendem com mais facilidade, pois utilizam diversos recursos cognitivos e tecnológicos no processo de sistematização e aplicação de conhecimentos. Interagem com imagens, sons, produções artísticas e textos de diferentes gêneros. Para Moran (1995), "o vídeo combina a comunicação sensorial-cinestésica, com a audiovisual, a intuição com a lógica, a emoção com a razão. Combina, mas começa pelo sensorial, pelo emocional e pelo intuitivo, para atingir posteriormente o racional." Esse trabalho envolve e embebe o aluno no desejo por mais e mais conhecimentos de diversos tipos, assim como valoriza e fomenta a criatividade.

Com efeito, abre-se um espaço para outro tipo de abordagem e sistematização dos conteúdos, a uma nova forma de escrita e leitura que transcende a ação pedagógica pontual da aula que se esgota ao seu encerramento. A utilização da informática no processo de ensinoaprendizagem permitiu a professora-pesquisadora e aos alunos imensa liberdade de expressão e reflexão sobre suas criações textuais. O computador possibilitou uma vastidão de alterações não lineares nos trabalhos escolares, dos mais simples aos mais complexos. O emprego de softwares de edição gráfica e de textos ampliou o objetivo da produção escrita, permitiu aos autores dos trabalhos: a criação, análise, correção, síntese, e adequação da linguagem em seus trabalhos, como maior eficiência e autoconfiança em relação aos procedimentos habituais de elaboração de trabalhos. Ver impressas as próprias ideias, o próprio olhar sobre o mundo gerou autoconfiança e prazer em aprender e conferiu significância ao ato de estudar.

A utilização do processo de produção do vídeo digital para abordar conteúdos de ensino, no contexto da sala de aula inspira a instauração de um processo de reflexão, construção e negociação de significados. Apresenta-se como propulsor para pensar a diversidade e a dinâmica da comunidade, constituindo uma situação de aprendizagem na qual os conteúdos de ensino são abordados nas suas dimensões conceituais, procedimentais e atitudinais. $O$ vídeo torna possíveis conexões não-lineares dos temas, conceitos ou situações-problema estudados e permite o compartilhar da construção e negociação de significados.

Desenvolve um ver entrecortado com múltiplos recortes da realidade - através dos planos - e muitos ritmos visuais: imagens estáticas e dinâmicas, câmera fixa ou em movimento, uma ou várias câmeras, personagens quietos ou movendo-se, imagens ao vivo, gravadas ou criadas no computador. Um ver que está situado no presente, mas que o interliga não linearmente com o passado e com o futuro. O ver está, na maior parte das vezes, apoiando o falar, o narrar, o contar histórias. A fala aproxima o vídeo do cotidiano, de como as pessoas se comunicam habitualmente. Os diálogos expressam a fala coloquial, enquanto o narrador (normalmente em off) "costura" as cenas, as outras falas, dentro da 
norma culta, orientando a significação do conjunto. A narração falada ancora todo o processo de significação (MORAN,1995)².

Trazer esse processo à sala de aula atribui importância à aquisição e ao desenvolvimento de habilidades na utilização de ferramentas da tecnologia da informação e comunicação, e, notadamente, o emprego de softwares para edição de imagens e sons. A elaboração do vídeo digital requer a utilização de equipamentos como filmadora, máquina fotográfica, computadores e softwares. O que a diferencia em objetivos e em recursos de uma produção cinematográfica clássica, cujo foco principal é o entretenimento, a diversão, a expressividade artística e semiótica. Assim sendo, os vídeos, também, trazem ao ensino um forte componente lúdico e artístico relevante à aprendizagem.

Por sua vez, o processo de produzi-lo possibilita ao educando a articulação e a produção de uma rede de saberes que transitam por vários campos disciplinares conectando-os as práticas sociais e aos problemas reais. "O vídeo é sensorial, visual, linguagem falada, linguagem musical e escrita. Linguagens que interagem superpostas, interligadas, somadas, não separadas" (MORAN, 1995) ${ }^{3}$. Com isso, tenciona-se a realidade e possibilita-se explorá-la por inúmeros pontos de vista.

Assim, valer-se desse recurso enquanto situação de aprendizagem importa em utilizar, preferencialmente, softwares com licenças gratuitas, códigos abertos e/ou populares, para tornar viável essa possibilidade aos professores e alunos. Nos vídeos desenvolvidos durante o processo de ensino efetivado foram utilizados os seguintes softwares: Microsoft Office Word 2007, editor de texto; Microsoft Office Publisher 2007, ferramenta de produção gráfica; Audacity 1.3 Beta (Unicode), editor de áudio; Microsoft Windows Movie Maker 6.0/2007, editor de vídeos; DVDStyler autorador de DVD; e Any Vídeo Converter 3.0.7.0 conversor de arquivos (decodificadores-codificadores).

Os vídeos apresentam os seguintes componentes: o roteiro que corresponde ao detalhamento de tudo que será produzido no vídeo, um plano de elaboração que contempla o planejamento do conteúdo áudio-visual; o storyboard refere-se ao detalhamento das sequências e ao encadeamento de imagens e sons a serem inseridos no editor de vídeos, isto é, a sequência de exibição do conteúdo, que podem ser imagens e/ou sons tais como fotografias, filmagens ou artes gráficas, a narração, músicas ou outros tipos de trilha sonora ou sons que se façam necessários à produção. A trilha sonora e a narração são produzidas em editores de áudio e inseridas no editor de vídeos, em sincronia com as imagens, seguindo-se o roteiro ou plano de produção.

\footnotetext{
${ }^{2}$ Documento sem paginação. Disponível em: http://www.eca.usp.br/prof/moran/vidsal.htm\#vespelho

${ }^{3}$ Documento sem paginação. Disponível em: http://www.eca.usp.br/prof/moran/vidsal.htm
} 
Na proposta de ensino posta em ação utilizou-se como roteiro a estrutura e os mesmos passos metodológicos do trabalho acadêmico em sua forma escrita - a situação-problema, a metodologia, a apresentação dos resultados, a sua discussão e as considerações finais. E optou-se por transformar em storyboard todo o material produzido ao longo do percurso dos projetos de investigação. Assim, integraram essa produção os dados obtidos por meio de fotografias e filmagens, referentes às situações-problemas elegidas para estudo a partir do ambiente local, tais como: entrevistas com pessoas da comunidade, informações científicas obtidas em periódicos científicos eletrônicos, livros e manuais acadêmicos, além de músicas consideradas pelos alunos relacionadas às situações-problemas. Dessa forma, todo esse conjunto de elementos, emergidos na dinâmica de realização dos projetos de trabalho, foi organizado em um plano narrativoargumentativo exibido nos vídeos produzidos.

Por conseguinte, o foco narrativo e o conjunto imagético, exibidos em cenas que compuseram o storyboard de cada vídeo, articularam a produção de cada projeto realizado, encadeando uma teia de significados que se entrelaçaram entre si. No entanto, ao transitar do registro escrito para o registro imagético, os textos redigidos para a narração, presentes nos vídeos, mudaram de configuração. E assim, passaram a articular a mobilização dos recursos de sons, imagens e artes gráficas, que compõem narrativas e representações e se expressaram por meio de uma fala próxima à coloquial, no intuito de efetivar o entendimento de seu conteúdo ao interlocutor e manter-se próximo ao cotidiano e à forma habitual de comunicação entre as pessoas.

Em geral, o texto que intenciona expressar conteúdo científico se pauta por um caráter de impessoalidade e negação de evocações emotivas, predominando o rigor, a organização, a abstração e a análise lógica. Por sua vez, os vídeos, embora, se caracterizem por uma linguagem concreta e plástica (MORAN, 1995), nas produções textuais que geraram para ancorar e produzir as ações narrativas, eles evocaram o emprego de metáforas, mesmo na abordagem de temas com conteúdo científico. Pois, quando articularam conceitos, axiomas e temas, os situaram em um contexto vivenciado, em uma prática social, em torno da qual foi tecida uma rede de significados resultante em uma produção onde o emocional, o afetivo e o racional interagiram e se integraram. E esses foram importantes para o estabelecimento das relações e nexos entre os conceitos estudados e a realidade retratada, explorada e exposta para ser conhecida e elucidada.

Para Paleari e Biz (2010, p. 500) "a força de uma narrativa não está apenas no seu tema, mas, antes de tudo, na força do componente imaginativo que propicia e que potencializa ao colocar as pessoas diante do inusitado, do contraditório e da não linearidade das imagens." Desse modo, os vídeos produzidos findam por documentar o estudo de uma situação-problema e a ação de seus protagonistas e colaboradores nessa empreitada pedagógica. Produzir vídeo em educação é experimentação, ensaio-e-erro e aprendizagem (CARNEIRO, 2002). 
Embora cada trabalho, sistematizado por meio do vídeo, aborde uma situação-problema específica, - como a água chega às casas, o porquê do padrão alimentar da população urbana, os efeitos das formas de transporte sobre a vida da população local e sua relação com a dinâmica dos ciclos do ambiente, e a leishmaniose tegumentar americana (doença de impacto social na comunidade) - todos erigem nexos entre os conceitos científicos, aspectos, políticos e econômicos que se entrelaçam na compreensão da realidade, pois, constituem facetas de uma mesma realidade vivenciada por todos. Esses quatro trabalhos constroem um quadro no qual os problemas sociais e ambientais estão imbricados, e explorá-los no processo de ensino remete o trabalho pedagógico aos vínculos com a "formação de cidadãos e sujeitos históricos, e a sua inserção autônoma no mundo" (VASCONCELOS; LOUREIRO; QUEIROZ, 2010) .

Assim sendo, as produções digitais evocam à escola, ao contexto da prática do ensino, a contextualização e a problematização dos conteúdos de ensino, fundamentadas em uma concepção de ciência e de educação conectada com emancipação e a conquista da cidadania. "A cidadania entendida em sua dimensão planetária, de ação social cotidiana, na qual a questão ecológica ocupa um papel central" (NARDI, 2007, p.8), pois a vida obviamente se processa em uma intrincada teia de múltiplas relações biológicas, culturais políticas e econômicas. A abordagem de ensino utilizada desnaturaliza a natureza, e desneutraliza a ciência para inscrevêlas em uma produção cultural e, portanto, apresentá-la como fruto da ação, da opção e intenção humana.

Desta maneira, explicita-se que a natureza e as ciências de referência que dela derivam, quando tomadas por objeto de estudo, "não preexistem a si mesmas, não estão à espera, prontas a serem descobertas por um método próprio para enxergá-la ou interpretá-la, como enunciava Bacon (1973) em seu Novum Organum" (CHAVES, 2010, p. 202). Do mesmo modo, os trabalhos resultantes do processo de ensino empreendido permitem enfrentar a idéia frequente nos cursos de formação de professores de ciências, apresentada por Leal (2010) da ciência distante da sala de aula, da escola da Educação Básica. Para o autor,

Nas universidades públicas, notadamente as Estaduais e Federais, a formação do professor de Ciências da Natureza padece de excessos de Biologia, Física e Química em relação ao que vem a ser dar aulas, ser professor, ensinar uma Ciência da Natureza. A docência fica atrás da Natureza que fica atrás da Ciência. O lugar de viver a Ciência é um lugar especial e muito distante das escolas de Ensino Médio e Ensino Fundamental (LEAL, M. C. 2010, p. 187).

\footnotetext{
${ }^{4}$ Documento sem paginação. Disponível em: http://www.fae.ufmg.br/abrapec/revista/index.html
} 
Portanto, nesse enfrentamento cabe explicitar que sociedade, natureza e cultura não se separam, apenas, aparentemente, parecem pertencer a campos disciplinares. A interação humana com a natureza é mediada pela cultura, e para exercitar a leitura da natureza é imprescindível à compreensão dos processos sócio-históricos articulados com os processos ecológicos e a valorização da cultura (LEFF, 1986; DIEGUES, 2008; MAYER, 2010, NOVICK, 2010; LOUREIRO, 2010). Desta maneira, "a natureza continuamente vem se construindo pela inserção do elemento humano como parte do mundo natural e como produtor de cultura" (MAYER, 2010, p. 135).

Portanto, para aprender e apreender desse e nesse universo de relações é essencial ultrapassar os limites da sala de aula, e ao mesmo tempo, articular os conhecimentos emergidos do contexto vivencial com a compreensão da natureza da ciência e da sua relação com a sociedade e a cultura (MC COMAS, 2000; REIS e GALVÃO, 2005). Para, com isso, promover-se uma educação problematizadora, de caráter reflexivo, de desvelamento da realidade, na qual o diálogo se institui como o eixo para as reflexões sobre as contradições básicas da situação existencial (FREIRE, 1987; SANTOS e MORTIMER, 2009). É, portanto, o estabelecimento da relação dialógica em sala de aula e no âmbito das práticas escolares, o que possibilita a educação para a prática da liberdade, da autonomia e da emancipação dos sujeitos históricos.

\section{Considerações finais}

A realização de atividades de investigação na condução do processo de ensino suscita o uso de tecnologias da informação e comunicação. Contudo, parece paradoxal o uso de novas tecnologias em Educação Ambiental, uma vez que no âmago dos problemas socioambientais encontra-se, invariavelmente, uma relação ambígua e negativa com o uso de tecnologias predatórias que degradam não só o ambiente, mas, sobretudo, o ser humano. Entretanto, os recursos tecnológicos, como os computadores, e a telemática, máquinas fotográficas, filmadoras, gravadores dentre outros dispositivos eletrônicos, ainda não indispensáveis em sala de aula. Eles podem se utilizados fundamentados em uma ética humanitária e solidária e por um lado, favorecer efetivamente a construção de uma mentalidade de respeito à pessoa e ao ambiente, e por outro, permitir a atuação em redes e informação e viabilizar um processo de emancipação da pessoa, possibilitando a essa uma participação social cada vez mais democrática.

A confecção de vídeos digitais com os alunos é um processo pedagógico de possível concretização e acessível ao professor. Desde que, o mesmo tenha acesso aos recursos (equipamentos e softwares necessários), e esse aprenda a utilizar as ferramentas tecnológicas empregadas nesse tipo de elaboração desenvolvendo em si e em seus alunos habilidades cognitivas e informacionais. O domínio de recursos e ferramentas para a produção midiática, 
quando apropriado pelo professor pode impulsioná-lo à conquista de autonomia para a escolha e opção por materiais e recursos de ensino. $O$ uso desse conhecimento na produção da própria práxis pedagógica retira o professor da condição de mero expectador/consumidor de produções didáticas e o insere na condição de protagonista que explora e interpreta a própria realidade vivida, fazendo emergir suas conexões, conflitos, contradições.

No entanto, é de bom alvitre ressaltar que, apesar de viver-se em um mundo que se serve cada vez mais das novas tecnologias, essas ainda são uma realidade distante da maioria das escolas públicas brasileiras, sendo, portanto, necessário garantir e democratizar o acesso a esses meios. Pois, o não acesso a esses meios, em uma sociedade cada vez mais caracterizada como tecnológica, onde as relações de trabalho, com a cultura e com a natureza empregam e envolvem cada vez mais tecnologia implica em efetiva produção de exclusão social. Por conseguinte, não há como se negar a inserir-se neste mundo. 


\section{Referências}

ANY VIDEO CONVERTER. Any Video Converter Versão 3.0.7 Copyright C 2006-2010. Disponível em: http://www.baixaki.com.br/download/any-video-converter-free.htm. Acessado em: 19/07/2009.

BACON, F. Novum Organum. Coleção os pensadores; (Trad.e José Aluysio Reis de Andrade). 1a ed. - São Paulo: Abril Cultural, 1973.

BRANDÃO, Carlos Rodrigues. O que é educação. São Paulo: Brasiliense, 1985.

CARNEIRO da CUNHA, M.; ALMEIDA, M. B. (orgs.) Enciclopédia da Floresta. $O$ alto Juruá: práticas e conhecimentos das populações. São Paulo: Cia. das Letras, 2002.

CHAVES, S. N. Receita de bom professor todo mundo tem a sua, eu também tenho a minha. In: ENCONTRO NACIONAL DE DIDÁTICA E PRÁTICA DE ENSINO. 15., 2010, Belo Horizonte.

Proceedings... Belo Horizonte: Autentica/UFMG, 2010. Coleção Didática e Prática de Ensino: Educação Ambiental, Educação em Ciências, Educação em Espaços Não-escolares, Educação Matemática, Belo Horizonte: Autêntica, 2010.

DEMO, P. Educar pela pesquisa. 8a Ed. São Paulo: Autores Associados, 2009.

FREIRE, P. Pedagogia do oprimido. 17 ed. Rio de Janeiro, Paz e Terra, 1987.

HERNÁNDEZ, F. Transgressão e mudança na educação os projetos de trabalho. Porto Alegre, ArtMed, 1998.

LAYRARGUES, P. P. A resolução de problemas ambientais deve ser um tema-gerador ou atividade fim da educação ambiental. In: REIGOTA, M. (Org.). Verde cotidiano: o meio ambiente em discussão. Rio de Janeiro: DP\&A, 1999, p. 131-148.

LAVILLE, C. DIONNE, J. A construção do saber: manual de metodologia da pesquisa em ciências humanas. (Trad. Heloisa Monteiro e Francisco Settineri) - Porto Alegre:Artmed; Belo Horizonte: Editora UFMG, 1999.

LOUREIRO, F. B. A relação teoria-prática na formação de professores em Educação Ambiental. In: ENCONTRO NACIONAL DE DIDÁTICA E PRÁTICA DE ENSINO. 15., 2010, Belo Horizonte.

Proceedings... Belo Horizonte: Autentica/UFMG, 2010.

LÜDKE, M. ANDRÉ, M. E. D. A. A. Pesquisa em Educação: abordagens qualitativas. 2ª̣ed, São Paulo: EPU, 1996.

MARTIANI, L. A. O vídeo e a pedagogia da comunicação no ensino universitário. In: PENTEADO, H. L. Pedagogia da comunicação - Teorias e Práticas. Ed. Cortez, 1998. p. 151 - 195.

MAYER. M. A. A. Leituras ambientais um exercício e aprendizado cotidiano. In: ENCONTRO NACIONAL DE DIDÁTICA E PRÁTICA DE ENSINO. 15., 2010, Belo Horizonte. Proceedings... Belo 
Horizonte: Autentica/UFMG, 2010. Coleção Didática e Prática de Ensino: Educação Ambiental, Educação em Ciências, Educação em Espaços Não-escolares, Educação Matemática, Belo Horizonte: Autêntica, 2010.

MORAN, J. M. O vídeo na sala de aula. Revista Comunicação \& Educação. São Paulo, ECA-Ed. Moderna, v. 2, p 27-35, jan./abr., 1995. Disponível em:

<http://www.eca.usp.br/prof/moran/vidsal.htm\#vprodução>. Acessado em 05/08/2010.

MICROSOFT CORPORATION. Microsoft Windows. Versão XP Profissional 2007 Disponível em: $<$ http://www.microsoft.com>

MICROSOFT CORPORATION. Microsoft Office Publisher. 2007. Disponível em: http://www.microsoft.com

MICROSOFT CORPORATION. Microsoft Office Word. 2007. Disponível em: http://www.microsoft.com

MICROSOFT CORPORATION. Windows Movie Maker. Versão 5.1, 2007 Disponível em: http://www.microsoft.com/windowsxp/using/moviemaker/default.mspx>.

NARDI, H. C. Editorial cidadania em processo. Revista de Estudos Universitários. v. 33. n.1, jun. p. 7-10, 2007.

NOVICK, V. Educação Ambiental: desafios à formação/trabalho docente. In: ENCONTRO NACIONAL DE DIDÁTICA E PRÁTICA DE ENSINO. 15., 2010, Belo Horizonte. Proceedings... Belo Horizonte: Autentica/UFMG, 2010. Coleção Didática e Prática de Ensino: Educação Ambiental, Educação em Ciências, Educação em Espaços Não-escolares, Educação Matemática, Belo Horizonte: Autêntica, 2010.

PANTOJA, M. C. Os Milton: cem anos de história nos seringais. 2ed. Rio Branco-AC: EDUFAC, 2008. POSTIGO, A. A. et. al. Atlas histórico do Rio Bagé (1907 - 2006). Campinas: IFCH/UNICAMP, 2008. SANTOS, W. L. P. e MORTIMER, E. F. Abordagem de aspectos sociocientíficos em aulas de ciências: possibilidades e limitações. Investigações em Ensino de Ciências . v.14, n.2, p. 191-218, 2009.

SHEWBRIDGE, W.; BERGE, Z. L. The role of theory and technology in learning video production: the challenge of change. International Journal on E-Learning, v.3, n.1, p. 31-39, jan/mar. 2004. THIOLLENT, M. Metodologia da Pesquisa-Ação. 6 ed. São Paulo: Cortez, 1994.

THUERING, A. DVDStyler versão 1.7.4. Licença GNU General Public License (GPL). Copyright (C 2009 Disponível em: http://www.baixaki.com.br/dowload/dvdstyler.htm. Acessado:10/08/2009.

VARGAS, A.; ROCHA, H. V.; FREIRE, F. M. P. Promídia: produção de vídeos digitais no contexto educacional. Novas Tecnologias na Educação - UFRGS/CINTED. v. 5, n. 2, dez. 2007. Disponível em: http://www.cinted.ufrgs.br/ciclo10/artigos/1bAriel.pdf Acessado em: 05/08/2010. 
VASCONCELLOS, M. M. N.; LOUREIRO, C. F. B.; QUEROZ, G. R. P. C. A Educação Ambiental e a Educação em Ciências: uma colaboração no enfrentamento da crise socioambiental. Revista Brasileira de Pesquisa em Educação em Ciências. v. 10, n. 1, 2010. Disponível em:

http://www.fae.ufmg.br/abrapec/revista/index.html Acessado em: 05/10/2010.

Murilena Pinheiro de Almeida - Universidade Federal do Acre - UFAC/Centro de Educação, Letras e Artes Rio Branco - Acre - murillena@gmail.com

Luis Maurício Martins de Rezende - Imresendee@gmail.com

Siumara Aprecida de Lima - Universidade Tecnológica Federal do Paraná - UTFPR/ Campus Ponta Grossa Ponta Grossa - Paraná - siumara@utfpr.edu.br 